\title{
Membranas de colágeno y quitosano de fuentes alternativas: evaluación para su uso potencial en ingeniería de tejidos
}

\section{Collagen and chitosan membranes from alternative sources: evaluation of their potential for Tissue Engineering applications}

\author{
Silvia E. Castro-Piedra ${ }^{1}$, Laura A. Calvo-Castro², Silvana Alvarenga- \\ Venutolo ${ }^{3}$, Carolina Centeno-Cerdas ${ }^{4}$, Maikol Ramos-Madrigal ${ }^{5}$, José \\ Vega-Baudrit ${ }^{6}$, Vanessa Zamora-Mora ${ }^{7}$, Miguel Rojas-Chaves ${ }^{8}$
}

Fecha de recepción: 26 de octubre del 2014

Fecha de aprobación: 14 de enero del 2015

Castro-Piedra, S; Calvo-Castro, L. A.; Alvarenga-Venutolo, S; Centeno-Cerdas. C; Ramos-Madrigal, M; Vega-Baudrit, J; Zamora-Mora, V; Rojas-Chaves, M. Membranas de colágeno y quitosano de fuentes alternativas: evaluación para su uso potencial en ingeniería de tejidos. Tecnología en Marcha. Edición especial Ingeniería de Tejidos. Pág 58-68.

1 Ingeniera en Biotecnología. Profesora de la Escuela de Biología e Investigadora del Centro de Investigación en Biotecnología del Instituto Tecnológico de Costa Rica. costa Rica. Teléfono: (506)2550-9027. Correo electrónico: silviabiotec@gmail.com.

2 Ingeniera en Biotecnología. Máster en Microbiología. Profesora de la Escuela de Biología e Investigadora del Centro de Investigación en Biotecnología del Instituto Tecnológico de Costa Rica. Costa Rica. Teléfono: (506)25509027. Correo electrónico: ancalvo@itcr.ac.cr.

3 Máster en Ciencias de Fitomejoramiento. Profesora de la Escuela de Biología e Investigadora del Centro de Investigación en Biotecnología del Instituto Tecnológico de Costa Rica. Costa Rica. Teléfono: (506)2550-2479. Correo electrónico: salvarenga@itcr.ac.cr.

4 Ingeniera en Biotecnología. Máster en Ciencias Biomédicas. Profesora de la Escuela de Biología e Investigadora del Centro de Investigación en Biotecnología del Instituto Tecnológico de Costa Rica. Costa Rica. Teléfono: (506)2550-9027. Correo electrónico: ccenteno@itcr.ac.cr.

5 Licenciado en Química Industrial con énfasis en Polímeros. Universidad Nacional de Costa Rica. Costa Rica. Teléfono: (506)7075-1189. Correo electrónico: maikolramos@gmail.com.

6 Doctorado en Polímeros. Profesor catedrático del Laboratorio de Polímeros POLIUNA de la Universidad Nacional y Director del Laboratorio Nacional de Nanotecnología LANOTEC-CeNAT-CONARE. Costa Rica. Teléfono: (506)25195835. Correo electrónico: jvegab@gmail.com.

7 Maestría en Química. Universidad Nacional de Costa Rica. Costa Rica. Correo electrónico: vzamora4@gmail.com.

8 Microbiólogo. Doctor en Ciencias Naturales con énfasis en Bioquímica. Profesor de la Escuela de Biología y Coordinador del Centro de Investigación en Biotecnología del Instituto Tecnológico de Costa Rica. Costa Rica. Teléfono: (506)2550-9406. Correo electrónico: mirojas@itcr.ac.cr 


\title{
Palabras clave \\ Biopolímeros; fibroblastos; andamios; UV; rayos X.
}

\begin{abstract}
Resumen
Los polímeros naturales, como el colágeno y el quitosano, presentan características físicas, químicas y biológicas que los hacen buenos candidatos para usarlos como soportes análogos de matriz extracelular, con potenciales aplicaciones en la ingeniería de tejidos. En el presente trabajo se evaluaron membranas biopoliméricas de colágeno y quitosano de material considerado tradicionalmente de desecho en la industria pesquera, para el cultivo de fibroblastos dérmicos. Se emplearon matrices de 100\% colágeno, 100\% quitosano y colágeno:quitosano en proporciones 8:2, 2:8, 6:4 y 4:6, obtenidos a partir fuentes alternativas (cáscara de camarón y piel de tilapia). El principal reto para el empleo de estos materiales en aplicaciones biomédicas es su esterilización, para lo cual se evaluaron diferentes métodos, incluyendo tratamientos químicos (etanol, antibióticos y acetona) y físicos (rayos $\mathrm{X}$, radiación UVC). El único procedimiento que permitió la desinfección efectiva sin comprometer la integridad de los biomateriales fue la incubación con antibióticos y antimicóticos durante 48 horas. Además, se confirmó la adhesión y proliferación celular sobre las membranas. Estos resultados demostraron el potencial biomédico de estos materiales.
\end{abstract}

\section{Keywords}

Biopolymers; fibroblasts; scaffolds; UV; X-rays.

\begin{abstract}
Natural polymers such as collagen and chitosan possess physical, chemical and biological characteristics that make them good candidates as extracellular matrix scaffolds with potential applications in Tissue Engineering. In the present work, collagen and chitosan biopolymer membranes made from waste material, were evaluated for dermal fibroblasts cell culture. Several membrane compositions were analyzed, including 100\% collagen, 100\% chitosan, 8:2, 2:8, 6:4, 4:6 collagen-chitosan, obtained from alternative sources (shrimp shells and fish scales). Given that sterilization is one of the main challenges for using materials and devices in biomedicine, we evaluated different methods to achieve this, including chemical (ethanol, antibiotics and acetone) and physical (X-rays, UVC irradiation) treatments. Antibiotic and antifungal immersion for 48 hours was the only procedure that allowed complete sterilization without compromising the integrity of the membranes. Also, we were able to confirm cellular adhesion and proliferation on the membranes. These results demonstrate the potential of these materials to be used as scaffolds in Tissue Engineering applications.
\end{abstract}


Tecnología en Marcha,

60 Edición especial Ingeniería de Tejidos

\section{Introducción}

La matriz extracelular de los tejidos animales está constituida por un entrelazado de heteropolisacáridos y proteínas fibrosas, que sostienen a las células para que se mantengan juntas y proveen de vías porosas para la difusión de nutrientes y oxígeno a las células individuales (Nelson y Cox, 2005). La reconstrucción de órganos y tejidos humanos in vitro requiere reconstruir la estructura de la matriz extracelular natural; en este sentido, diversos biopolímeros de origen natural o sintético han demostrado que pueden servir como soportes bidimensionales o tridimensionales para el cultivo celular (Han et al., 2010), promoviendo la adhesión, el crecimiento y la diferenciación (Zhong, Zhang y Lim, 2010). Los polímeros naturales como el colágeno y el quitosano han sido ampliamente utilizados como andamios aplicados en la ingeniería de tejidos: Integrar $\AA$, Regen Menaflex®, Ologen $®$ (Jana et al., 2012; Parenteau et al., 2010 y Van Essen et al, 2013).

El colágeno es una proteína fibrosa secretada por las células en los tejidos conectivos (Nelson y Cox, 2005). Además, es uno de los principales componentes estructurales del hueso, el cartílago y la piel (Chen et al., 2009) y se le considera uno de los biomateriales más prometedores para el desarrollo de aplicaciones biomédicas en ingeniería de tejidos, especialmente para la reconstrucción de piel, debido su excelente biocompatibilidad y degradabilidad, así como por su baja antigenicidad y abundante disponibilidad en mamíferos (Han et al., 2010).

El quitosano es un derivado desacetilado de la quitina, un polisacárido linear no ramificado presente principalmente en el exoesqueleto de los crustáceos y en micelios fúngicos (Howling et al., 2001). En la última década ha sido ampliamente utilizado para aplicaciones en ingeniería de tejidos debido a su biocompatibilidad, biodegradabilidad y capacidad de acelerar la regeneración de tejidos y la síntesis de colágeno (Chen et al., 2009). Además, se ha reportado que los productos de degradación del quitosano no son tóxicos ni alergénicos (Kim, Lee, Chung y Yang, 2009). Asimismo, se ha observado que las membranas de quitosano proveen estabilidad mecánica y flexibilidad, mayor captación de agua y tienen propiedades bacteriostáticas y fungistáticas (Johnen et al., 2008).

Aunque el colágeno y el quitosano no existen juntos como mezcla en la naturaleza (ZamoraMora, Sibaja y Vega-Baudrit, 2010), se ha reportado que matrices que combinan ambos componentes son excelentes candidatas para la reconstrucción in vitro de sustitutos de la piel, ya que proveen mayor bioestabilidad y excelente biocompatibilidad (Han et al., 2010).

Considerando el gran potencial de los biopolímeros en la ingeniería de tejidos y la medicina regenerativa, el Laboratorio de Ingeniería de Tejidos del Centro de Investigación en Biotecnología del Instituto Tecnológico de Costa Rica (ITCR), en colaboración con el Laboratorio de Polímeros de la Universidad Nacional (UNA), realizó la evaluación preliminar de un biomaterial de colágeno y quitosano, con el fin de determinar su potencial uso como andamio para el cultivo de células epiteliales para aplicaciones terapéuticas en Costa Rica.

\section{Metodología}

\section{Elaboración de las membranas}

La elaboración de las membranas se llevó a cabo empleando colágeno y quitosano como sustrato. El quitosano grado técnico se obtuvo a partir del material de desecho pesquero de camarón camello (Heterocarpus vicarius). Este sustrato lo proporcionó el Laboratorio de Investigación de Polímeros de la Universidad Nacional (POLIUNA). La purificación del quitosano se realizó usando la metodología descrita por Esquivel, Moya, Sibaja y Calvo (2004). 
El proceso de extracción de colágeno se hizo de acuerdo con la metodología adaptada por Zamora y colaboradores (2010), en el cual la purificación y caracterización del colágeno obtenido se lleva a cabo a partir de pieles de tilapia (Oreochromis niloticus).

La posterior elaboración y caracterización de las membranas de 100\% m/v colágeno, 100\% m/v quitosano y colágeno:quitosano en proporciones 8:2, 2:8, 6:4 y 4:6, respectivamente las realizó el POLIUNA y se llevó a cabo de acuerdo al procedimiento descrito por Zamora-Mora, Ramos, Sibaja y Vega-Baudrit (2012).

Pruebas de esterilización

Inmersión en etanol 70\%. Cada tipo de membrana fue sumergido en etanol 70\% (filtrado, 0,22 $\mu \mathrm{m})$. Se probaron dos tratamientos de 45 minutos y 4 horas en los que las membranas se dejaron en agitación constante.

Exposición a luz UV (200-300nm). Las membranas se expusieron a luz UV (200-300nm) en un ambiente estéril durante 8 horas ( 4 horas por lado) y 48 horas (24 horas por lado). Posteriormente se mantuvieron en la oscuridad durante 12 horas.

Inmersión en antibióticos y antimicóticos. Las membranas se sumergieron en una solución de antibióticos y antimicóticos (fluconazol $100 \mu \mathrm{g} / \mathrm{ml}$, anfotericina B 0,3 $\mu \mathrm{g} / \mathrm{ml}$, vancomicina $50 \mu \mathrm{g}$ / $\mathrm{ml}$, imipenem $96 \mu \mathrm{g} / \mathrm{ml}$ ), disueltos en medio de cultivo, durante 16,24 , y 48 horas a $37^{\circ} \mathrm{C}$.

Exposición a óxido de etileno. Las membranas se empacaron en bolsas permeables al gas (con indicador bioquímico de esterilidad) y se esterilizaron en una cámara de óxido de etileno en un hospital local.

Exposición a rayos $X$. Los segmentos de membrana se expusieron a una dosis de rayos $X$ equivalente a 50 Gy en el Laboratorio de Ensayos no Destructivos de la Escuela de Ingeniería en Materiales del ITCR.

Inmersión en alcohol 70\% y acetona. Las muestras se sumergieron en alcohol 70\% (filtrado, 0,22 $\mu \mathrm{m}$ ), durante 5 minutos. Seguidamente se sumergieron en acetona (filtrada, 0,22 $\mu \mathrm{m}$ ) durante 5 minutos y se lavaron dos veces con PBS. Para cada método de esterilización se realizaron controles de contaminación microbiana en Agar Papa Dextrosa (APD) y en Agar de Recuento Estándar (ARE). Además, se llevaron a cabo comparaciones espectroscópicas infrarrojas de las membranas luego de cada tratamiento (excepto la inmersión en alcohol $70 \%$ - acetona y la exposición a rayos $\mathrm{X}$ ) con el fin de evaluar cambios en las características físico-químicas originales de los apósitos.

Evaluación de las membranas en las condiciones de cultivo. Se sumergió una muestra de cada membrana en medio de cultivo celular para fibroblastos (DMEM suplementado con 10\% de suero fetal bovino (SFB), 2\% glutamina [4 mM], 1\% penicilina-estreptomicina [10000 u/ml penicilina $\mathrm{G}, 10000 \mu \mathrm{g} / \mathrm{ml}$ sulfato de sulfato de estreptomicina] y $1 \%$ piruvato de sodio [0.11 $\mathrm{mg} / \mathrm{ml}$, con un $\mathrm{pH}$ final de $7,5-7,7)$. Las muestras se incubaron durante una semana a $37^{\circ} \mathrm{C}$ y $5 \% \mathrm{CO}_{2}$. Se realizaron controles microbiológicos en ADP y ARE. Dado que el proceso para la obtención de las membranas implica la disolución de los polímeros en ácido acético (ZamoraMora et al., 2010), la acidez residual de las membranas redujo drásticamente el pH del medio de cultivo (figura 1a), lo cual sería desfavorable para el cultivo celular. Por ello, en adelante se realizaron tres lavados de 5 minutos con medio de cultivo a cada membrana antes de su utilización para el cultivo celular.

Evaluación de las membranas como soporte para el crecimiento de células dérmicas. Ensayos preliminares demostraron que las membranas flotaron, se contrajeron y se plegaron sobre sí mismas en el medio de cultivo celular (figura 1a). Además, se ha mostrado que cuando se usan membranas biopoliméricas como soporte para el cultivo de células dermales, la distorsión en 
los andamios puede causar cambios morfológicos y apoptosis en el cultivo celular, mientras que en membranas tensadas los fibroblastos humanos se alinean de forma más organizada y similar a su disposición in vivo (Castro-Piedra, 2009). Por ello, se confeccionaron aros de acero inoxidable que permitieron fijar y tensar espacialmente las membranas (figura 1b). Las membranas estériles fueron prensadas entre los aros (esterilizados por calor húmedo) y se inocularon con fibroblastos murinos $3 \mathrm{~T} 3\left(5 \times 10^{4}\right.$ células $\left./ \mathrm{ml}\right)$. Se utilizó el medio de cultivo estándar para fibroblastos y las mismas condiciones de cultivo descritas anteriormente. Luego de 48 horas, se incubó cada muestra con MTT $(0.5 \mathrm{mg} / \mathrm{ml}$ en medio de cultivo) por 2 horas; posteriormente, se removieron las membranas de los aros, se lavaron dos veces con PBS, se colocaron sobre un plato Petri con PBS y se observaron al microscopio.
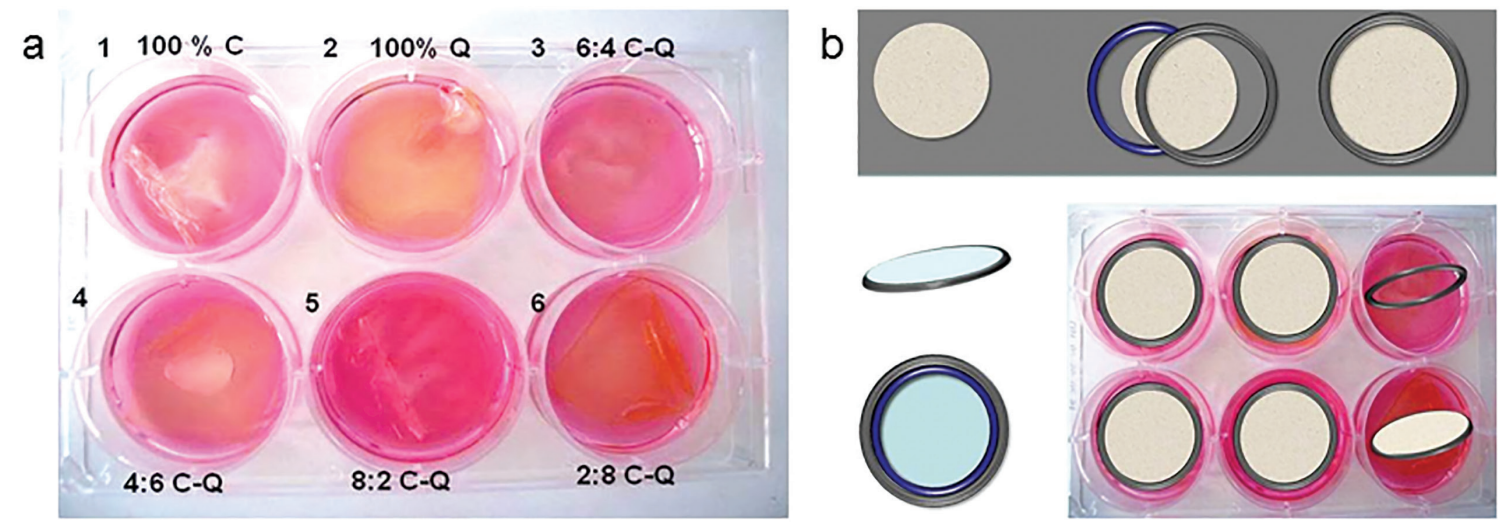

Figura 1. Matrices biopoliméricas inmersas en medio de cultivo para fibroblastos (a) y diseño de los aros metálicos tipo prensa como mecanismo de sujeción para las membranas biopoliméricas (b). Nótese que, en ausencia de los aros, las matrices no están sujetas a la superficie, se encuentran flotando y presentan arrugas y dobleces.

\section{Resultados y discusión}

Evaluación de los métodos de esterilización. La esterilización de las membranas biopoliméricas es fundamental para su uso en aplicaciones biomédicas. En este estudio (Cuadro 1), algunos de los métodos utilizados resultaron poco efectivos, ya que solo disminuyeron la carga microbiana, mientras que otros resultaron demasiado agresivos, afectando la integridad física y química de la matriz, lo que podría impedir la posterior adhesión y proliferación celular. A nivel macroscópico, se observó que los métodos de esterilización no alteraron significativamente la estructura de las membranas, a excepción de la esterilización con óxido de etileno.

Etanol $70 \%$. Después del tratamiento, las membranas se tornaron frágiles y quebradizas, lo que podría deberse al efecto deshidratante del etanol. El nivel de fragilidad observado fue proporcional al porcentaje de colágeno presente en la membrana. Por otro lado, a pesar de reducir la carga microbiana (datos no mostrados), no se obtuvo esterilización total de ninguna de las membranas con este método, ya que se detectaron contaminantes en todos los controles microbiológicos. Sin embargo, se ha reportado que una combinación alcohol-acetona o un mayor tiempo de incubación (24 horas) presentan mayor capacidad de desinfección (Han et al., 2010), tal y como se discute más adelante.

Luz UV (200-300nm). La luz UV forma radicales libres que oxidan las moléculas biológicas, rompe los enlaces dobles en proteínas causando su desnaturalización y genera la formación de dímeros de timina en el ADN. Lo anterior puede generar mutaciones que lleven a la 
transformación de las células de forma que comprometan su viabilidad (Boyce y Flanders, 1964). Ambos tiempos de incubación (8 y 48 horas) redujeron considerablemente la carga microbiana. Sin embargo, ninguno de los tratamientos logró eliminar los contaminantes fúngicos. Además, el potencial daño oxidativo a las proteínas que componen la membrana, así como la incapacidad de este tratamiento para esterilizar efectivamente, fueron criterios para descartar este método de esterilización.

Cuadro 1. Determinación de la presencia de contaminación microbiana presente en matrices de colágeno:quitosano sometidas a diferentes tratamientos de desinfección

\begin{tabular}{|c|c|c|c|c|c|c|c|c|c|c|c|c|c|}
\hline \multicolumn{2}{|c|}{ Tratamiento } & \multicolumn{2}{|c|}{$\begin{array}{c}100 \% \\
\text { Colágeno }\end{array}$} & \multicolumn{2}{|c|}{ 100\% Quitosano } & \multicolumn{2}{|c|}{$6: 4 \mathrm{C}-\mathrm{Q}$} & \multicolumn{2}{|c|}{$4: 6 \mathrm{C}-\mathrm{Q}$} & \multicolumn{2}{|c|}{$8: 2 C-Q$} & \multicolumn{2}{|c|}{$2: 8 C-Q$} \\
\hline & & APD & ARE & APD & ARE & APD & ARE & APD & ARE & APD & ARE & APD & ARE \\
\hline \multirow{2}{*}{$\begin{array}{c}\text { Alcohol } \\
70 \%\end{array}$} & $45 \mathrm{~min}$ & + & + & + & + & + & + & + & + & + & + & + & + \\
\hline & $4 \mathrm{~h}$ & + & + & + & + & + & + & + & + & + & + & + & + \\
\hline \multirow{2}{*}{ Luz UV } & $8 \mathrm{~h}$ & + & + & + & + & + & + & + & + & + & + & + & + \\
\hline & $48 \mathrm{~h}$ & $1^{*}$ & $1^{*}$ & $3^{*}$ & $0^{*}$ & $3^{*}$ & $0^{*}$ & $3^{*}$ & $0^{*}$ & $3^{*}$ & 0 & $3^{*}$ & $0^{*}$ \\
\hline \multirow{3}{*}{$\mathrm{AB} / \mathrm{AM}$} & $16 \mathrm{~h}$ & - & - & - & - & - & - & + & + & - & - & - & + \\
\hline & $24 \mathrm{~h}$ & - & - & + & - & - & - & - & - & - & - & - & - \\
\hline & $48 \mathrm{~h}$ & - & - & - & - & - & - & - & - & - & - & - & - \\
\hline OE & - & - & - & - & - & - & - & - & - & - & - & - & - \\
\hline Rayos X & 50 Gy & NR & NR & + & - & + & + & + & + & + & + & + & - \\
\hline Alcohol & Acetona & + & NR & + & NR & + & NR & + & NR & + & NR & + & NR \\
\hline
\end{tabular}

APD: agar papa dextrosa, ARE: agar de recuento estándar, OE: óxido de etileno,NR: no se realizó, AB: antibióticos, AM: antimicóticos, C: colágeno, Q: quitosano, + indica presencia de contaminantes (incontable), * expresado en UFC (unidades formadoras de colonias).

Antibióticos y antimicóticos. El único tratamiento que logró esterilizar todas las muestras evaluadas fue la exposición a una mezcla de antibióticos y antimicóticos por 48 horas. Aunque este tratamiento demostró ser efectivo para la esterilización de las membranas, es laborioso y costoso. Además, implica el riesgo de crear bacterias resistentes a antibióticos o enmascarar la presencia de microorganismos de baja tasa de replicación.

Óxido de etileno. Aunque este tratamiento también fue efectivo para esterilizar completamente las membranas, estas se observaron frágiles y oscurecidas, lo que sugiere que sufrieron oxidación relevante, lo cual es esperable ya que este gas basa su efectividad precisamente en una alta capacidad oxidativa de las moléculas biológicas. En efecto, como se observa en los resultados de espectroscopía infrarroja, este tratamiento fue el que causó mayores alteraciones en la composición química de las membranas (figura 2). El daño a la estructura química de las membranas descarta este procedimiento, ya que es deseable alterar lo menos posible su composición original.

Exposición a rayos $X$. Los ensayos de control microbiológico para la evaluación de la esterilidad indicaron que este método de esterilización no fue efectivo, ya que se presentó contaminación variable. Esto puede deberse a que la dosis de irradiación empleada fue relativamente baja, 
por lo que se recomienda repetir estas pruebas utilizando la dosis de esterilización internacional estándar adoptada por la OIEA (25 kGy) para la esterilización de productos médicos, la cual provee un nivel de aseguramiento de la esterilidad (SAL, por sus siglas en inglés) de 10-6 (Lobo Gajuwala, 2003). Sin embargo, esta dosis de irradiación no es alcanzable con el equipo de rayos $X$ disponible en el ITCR, ya que está equipado con una fuente de baja intensidad.

Inmersión en alcohol 70\% y acetona. Este ensayo de esterilización fue efectivo para reducir significativamente la carga microbiana. No se observaron contaminantes fúngicos en la primera semana de evaluación de los controles microbiológicos; sin embargo, todas las muestras incubadas en agar papa dextrosa mostraron contaminantes a las 2 semanas de incubación. Además, estas muestras también fueron evaluadas mediante incubación en caldo tioglicolato, y no se encontró turbidez luego de una semana de incubación a $37^{\circ} \mathrm{C}$.

Alteraciones físico-químicas de las membranas ante los diferentes métodos de esterilización. En las membranas de 100\% colágeno y 100\% quitosano, conforme aumentó el tiempo de exposición a los antibióticos, ocurrió mayor alteración química de las membranas (figura 2). Los otros tratamientos evaluados también causaron alteraciones, principalmente el óxido de etileno.
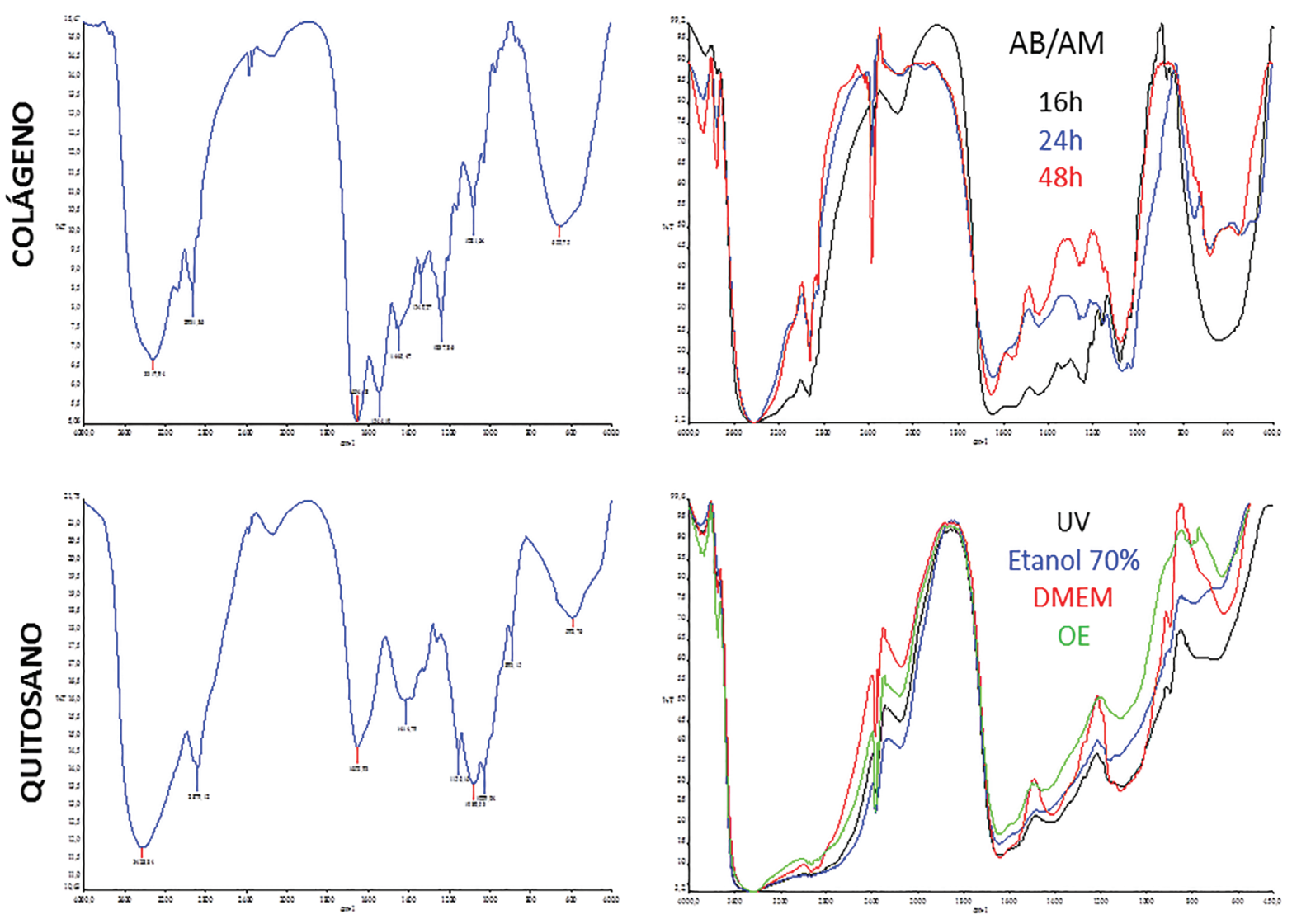

Figura 2. Espectro infrarrojo (derecha) de colágeno obtenido de piel de tilapia (Oreochromis niloticus) y quitosano obtenido de cáscara de camarón (Heterocarpus vicarius). Se muestra el \% de tramitancia vs. la banda de absorción $\left(\mathrm{cm}^{-1}\right)$. A la izquierda, se muestra una membrana de quitosano 100\% y una membrna de colágeno 100\% sometidas a diversos procesos de esterilización. Los resultados para el quitosano en antibióticos y antimicóticos (AB/AM) y para el colágeno con los otros tratamientos fueron (UV: irradiación ultravioleta, DMEM: control no tratado y mantenido en medio de cultivo, OE: óxido de etileno) muy similares y no se muestran. Fuente: Laboratorio de Polímeros, UNA. 
Los resultados de espectrometría infrarroja fueron similares en las matrices compuestas por 6:4 colágeno-quitosano y 4:6 colágeno-quitosano (datos no mostrados); no obstante, estas modificaciones fueron menos drásticas en comparación con la membrana 100\% colágeno. Lo anterior también se reflejó en los análisis de las matrices 8:2 colágeno-quitosano, lo cual confirma que estos dos polímeros mezclados en las diferentes proporciones presentan mayor estabilidad que de forma individual (figura 3). Además, se observó que a mayor proporción de colágeno y menor cantidad de quitosano, ocurrieron menores variaciones (Fig. 4). Lo anterior sugiere que la estabilidad química de las membranas evaluadas durante su esterilización y en condiciones de almacenamiento fue directamente proporcional a la cantidad de colágeno presente en la membrana.

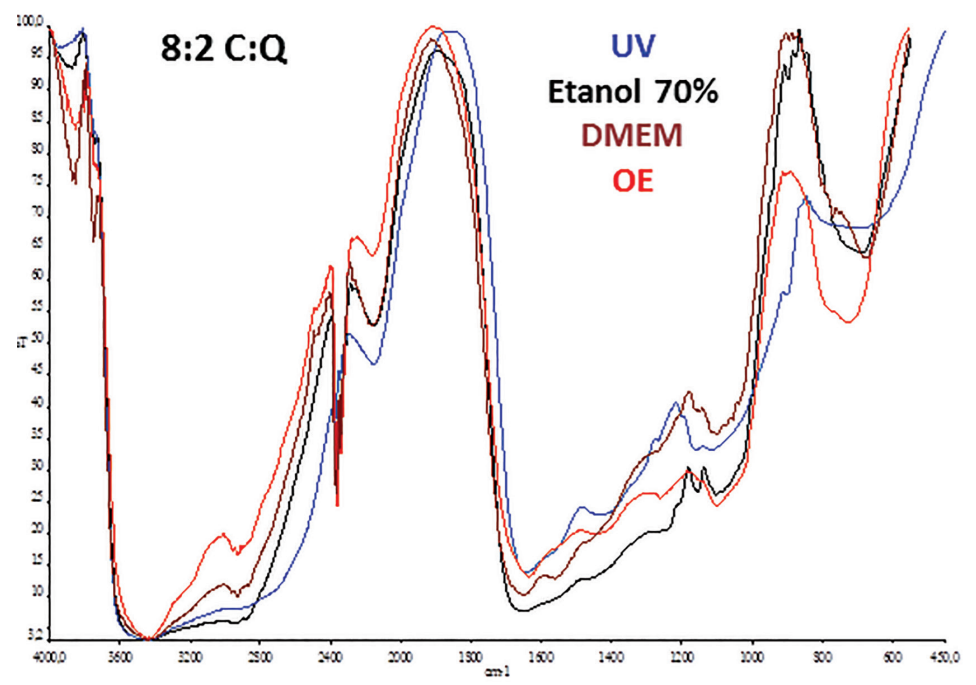

Figura 3. Comparación espectroscópica infrarroja (FITR) para una película de 8:2 colágeno-quitosano (C:Q), sometida a diversos procesos de esterilización, mostrados en diferentes colores. Se muestra el \% de tramitancia vs. la banda de absorción (cm-1). Fuente: Laboratorio de Polímeros, UNA. UV: irradiación ultravioleta, DMEM: control no tratado y mantenido en medio de cultivo, OE: óxido de etileno.

Evaluación de las matrices poliméricas como soporte para el crecimiento de células dérmicas. Luego de un periodo de 24-36 horas de incubación en condiciones de cultivo celular, se observó que las matrices 100\% colágeno se disolvieron por completo en el medio de cultivo para fibroblastos. Por lo tanto, en estas nuevas condiciones se observó una relación proporcional entre la cantidad de quitosano presente y la estabilidad estructural de la membrana. Por ejemplo, las membranas 8:2 colágeno:quitosano se rompieron en trozos y presentaron desgarres luego de una semana bajo las condiciones de cultivo celular. Por otro lado, al ser colocadas en una solución acuosa, las matrices presentaron la tendencia a hidratarse, a plegarse sobre sí mismas, flotar y contraerse. Esto dificultó la inoculación de células de manera homogénea sobre las matrices y la observación al microscopio para el seguimiento del crecimiento celular sobre las membranas. Sin embargo, con el uso de los aros metálicos tipo prensa, esta situación mejoró y permitió la adhesión y proliferación de los fibroblastos en las membranas 6:4, 4:6 y 2:8 colágeno:quitosano, de tal forma que los fibroblastos crecieron de manera normal sobre la membrana, lo que indica que las matrices y los aros no tuvieron efectos citotóxicos observables sobre las células (figura 5). Esto concuerda con experimentos reportados por otros autores que han utilizado andamios de quitosano recubiertos con colágeno, en los que el quitosano provee el soporte estructural y el colágeno favorece la adhesión celular (Chen et al., 2009). 

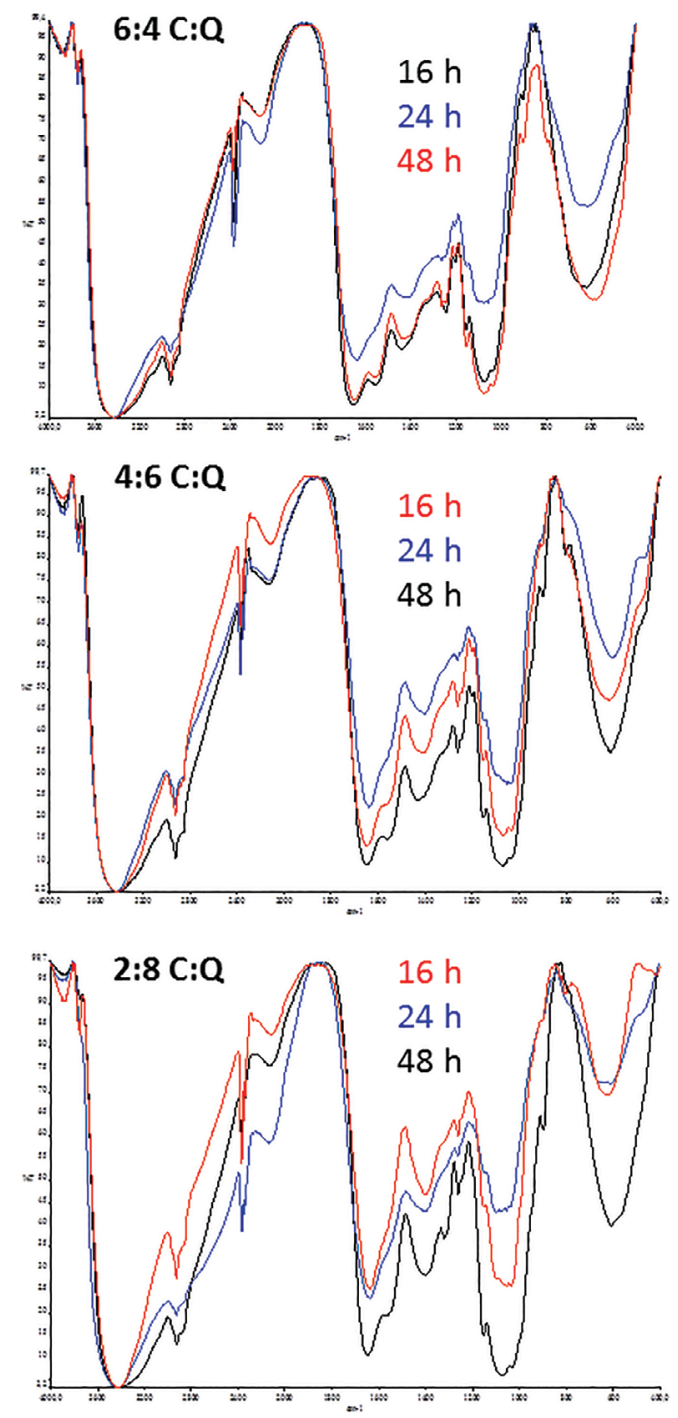

Figura 4. Comparación espectroscópica infrarroja (FITR) membranas de 6:4, 4:6 y 2:8 colágeno:quitosano (C:Q), sometidas a diversos tiempos de esterilización (16, 24 y 48 h) ante una solución de antibióticos y antimicóticos. Se muestra el \% de tramitancia vs. la banda de absorción (cm-1). Fuente: Laboratorio de Polímeros, UNA.
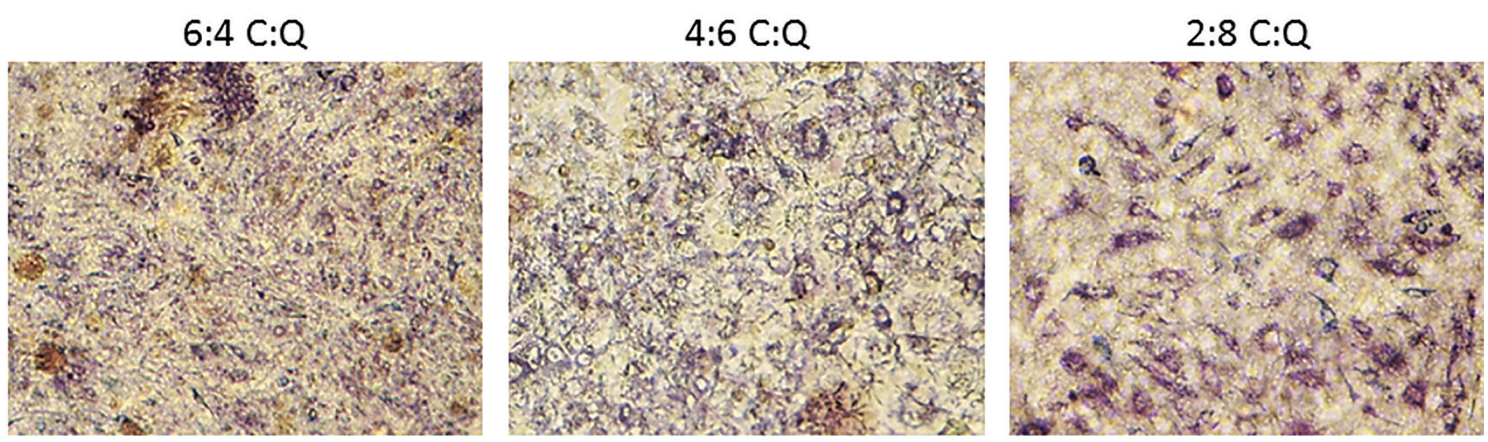

Figura 5. Membranas de 6:4, 4:6 y 2:8 colágeno:quitosano inoculadas con fibroblastos 3T3 (100x) teñidos con MTT 
luego de 48 horas de incubación. El MTT tiñe de color morado únicamente las células metabólicamente viables.

\section{Conclusiones}

Los métodos de esterilización utilizados no resultan por completo satisfactorios desde una perspectiva de costo-efectividad. Los ensayos realizados para evaluar la adhesión de fibroblastos a los andamios de colágeno y quitosano indicaron que las células requieren soportes con cierta tensión para que no se vean afectados aspectos de su fisiología como la organización del citoesqueleto. No obstante, bajo las condiciones evaluadas, se observó que la presencia de las membranas no interfiere con el crecimiento y la proliferación celular, lo cual sugiere que las membranas no son citotóxicas. Por otro lado, la proporción colágeno:quitosano es un factor importante a considerar en la preparación de estos apósitos, puesto que influye tanto en la estabilidad de la membrana como en la adhesión celular. Además, es imperativo estandarizar el protocolo de esterilización y optimizar el mecanismo de sujeción adecuado para la tensión de las matrices.

\section{Agradecimientos}

Este proyecto fue financiado por el Fondo Estatal para la Educación Superior (FEES). Los autores agradecen al Laboratorio de Investigación de Polímeros de la Universidad Nacional (POLIUNA, Costa Rica) y al Laboratorio Nacional de Nanotecnología LANOTEC-CeNAT-CONARE, por el aporte de las membranas para la realización del estudio, por la caracterización física y química de las membranas; a la estudiante Diana Michelle López Fonseca (ITCR), por la elaboración de los aros de sujeción y el análisis de esterilización mediante rayos X; a los estudiantes Rebecca Nieto (UNA) y José Valverde (ITCR), por el cultivo celular utilizando los aros de sujeción; y a la estudiante Susana Acosta González (ITCR), por su colaboración en la redacción de este documento.

\section{Bibliografía}

Boyce, R. \& Flanders, P. (1964). Release of ultraviolet light-induce thymine dimers from DNA in E. coli K-12. Proc Natl Acad Sci, 51(2): 293-300.

Castro-Piedra, S. E. (2009). Modelos experimentales para aislamiento y mantenimiento in vitro de queratinocitos y fibroblastos humanos y su utilización en una matriz con potencial en ingeniería de tejidos. Informe de Trabajo Final de Graduación, Bachillerato en Ingeniería en Biotecnología, Escuela de Biología, Instituto Tecnológico de Costa Rica.

Chen, K-Y., Liao, W-J., Kuo, S-M., Tsai, F-J., Chen, Y-S., Huang, C-Y. \& Yao, C-H. (2009). Asymmetric chitosan membrane containing collagen I nanospheres for skin tissue engineering. Biomacromolecules. 10, 1642-1649.

Esquivel, M., Moya, M., Sibaja, M. \& Calvo, M. (2004). Obtención de quitosano grado farmacéutico a partir del langostino Pleuroncodes planipes. III Simposio Iberoamericano de Quitina (SIAQ). 116.

Han, C., Zhang, L., Sun, J., Shi, H., Zhou, J. \& Gao, C. (2010). Application of collagen-chitosan/fibrin glue asymmetric scaffolds in skin tissue engineering. Biomed \& Biotechnol, 11(7), 524-530.

Howling, G., Dettmar, P., Goddart, P., Hampson, F., Dornish, M. \& Wood, E. (2001). The effect of chitin and chitosan on the proliferation of human skin fibroblasts and keratinocytes in vitro. Biomaterials (22), 2959-2966.

Jana, S., Florczyk, S., Leung, M. \& Zhang. M. (2012). High-strength pristine porous chitosan scaffolds for tissue engineering. J. Mater. Chem, 22, 6291-6299.

Johnen, C., Steffen, I., Beichelt, D., Brautigam, K., Witascheck, T., Toman, N., Moser, V., Ottomann, C., Hartmann, B. \& Gerlach, J. C. (2008). Culture of subconfluent human fibroblasts and keratinocytes using biodegradable transfer membranes. Burns, 34(5), 655-663. 
Tecnología en Marcha,

68 Edición especial Ingeniería de Tejidos

Kim, N. R., Lee, D. H., Chung, P. \& Yang, H.-C. (2009). Distinct differentiation properties of human dental pulp cells on collagen, gelatin, and chitosan scaffolds. Oral Surg. Oral Med. Oral Patho.l Oral Radiol. Endod. 108, e94-e100.

Lobo Gajiwala, A. (2003). Tissue banking in India: Gamma-irradiated allografts. Cell and Tissue Banking 4, 203211.

Nelson, D. L. \& Cox, M. M. (2005). Lehninger Principles of Biochemestry. 4 ed. W. H. Freeman.

Parenteau, R., Gauvin, R. \& Berthod, F. (2010). Collagen-Based Biomaterials for Tissue Engineering Applications. Materials 3, 1863-1887.

Van Essen, T., Lin, C., Hussain, A., Maas, S., Lai, H., Linnartz, H., van den Berg, T., Salvatori, D., Luyten, G. \& Jager, M. (2013). A fish scale-derived collagen matrix as artificial cornea in rats: properties and potential. Invest. Ophthalmol Vis. Sci. 54(5), 3224-3233.

Zamora-Mora, V., Sibaja, M. \& Vega-Baudrit, J. (2010). Diseño de un biofilm a partir de colágeno de pieles de tilapia y de quitosano de camarón como soporte para aplicaciones en ingeniería de tejidos. Revista Iberoamericana de Polímeros, 11(7), 607-619.

Zamora-Mora, V., Ramos M., Sibaja M. \& J. Vega-Baudrit. (2012). Aprovechamiento de los desechos de las actividades acuícolas y pesqueras de Costa Rica para el Desarrollo de Biomateriales para aplicaciones en Ingeniería de Tejidos. Residuos Sólidos en Iberoamérica, 1, 312-356.

Zhong, S. P., Zhang, Y. Z. \& Lim, C. T. (2010). Tissue scaffolds for skin woundhealing and dermal reconstruction. Nanomedicine and Nanobiotechnology, 2, 510-525. 